\title{
Q Fever in the Differential Diagnosis of COVID-19 Infection
}

\author{
Sevil ALKAN ${ }^{1}$ (D) , Alper SENER ${ }^{1}$ (D) , Safiye Bilge GUCLU KAYTA ${ }^{1}$ (D) , Anil AKCA ${ }^{1}$ \\ ${ }^{1}$ Department of Infectious Disease, Canakkale Onsekiz Mart University, Faculty of Medicine, Canakkale, Turkey
}

Keywords: Q Fever, COVID-19, Coxiella burnetii.

Dear Editor,

Coronavirus Disease 2019 (COVID-19), which has disrupted most of the health services since the pandemic was declared since March 2020. The previously reported symptoms for COVID-19 possible case definition is quite wide. Fever, cough, shortness of breath, sore throat, headache, muscle aches, new loss of taste or smell, nausea or vomiting and diarrhea are among them. ${ }^{1,2}$ Due to the variability of symptoms, it should be considered in differential diagnosis with many diseases. In addition, sometimes the increased workload of health workers can cause other diseases to be misdiagnosed or delayed.

A 60-year-old male livestock worker presented with complaints of fever, headache, abdominal pain, nausea, vomiting, cough and sputum for 4-5 days. The patient had nor an intravascular device neither immunosuppressive condition. In physical examination; fever: $39^{\circ} \mathrm{C}$, his general condition was moderate-poor, lethargic, and his consciousness was drowsy. Oropharynx was hyperemic. On physical examination, meningeal irritation findings were negative and there were no additional pathological features. White blood cell: $4,300 / \mathrm{mm}^{3}$, lymphocyte count: $560 /$ $\mathrm{mm}^{3}$, neutrophil count: $3,260 / \mathrm{mm}^{3}$ hemoglobin: $11.8 \mathrm{gr} / \mathrm{dL}$, platelets: $127,000 / \mathrm{mm}^{3}$, C-reactive protein: $17.7 \mathrm{gr} / \mathrm{dL}$, erythrocyte sedimentation rate: 71/hour. Hepatic function test was normal. Postero-anterior chest radiography was normal. COVID-19 real time polymerase chain reaction (RT-PCR) test performed from the patient because the patient had signs of possible COVID-19 symptoms. The diagnosis of COVID-19 was ruled out due to insufficient scientific evidence as a result of negative COVID-19 PCR and absence of pulmonary radiological findings.

After obtaining the blood and urine cultures empirically, ceftriaxone $2 x 1 \mathrm{~g}$ IV treatment was initiated. Since central nervous system infection was not considered clinically, lumbar puncture was not performed to the patient. For differential

\begin{tabular}{|c|c|c|}
\hline & $\begin{array}{l}\text { Received: March 30,2021;Accepted: June 30,2021; Published Online: October 29,2021 } \\
\text { Address for Correspondence: } \\
\text { Sevil Alkan, } M D\end{array}$ & 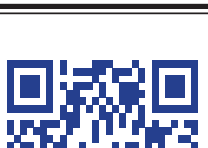 \\
\hline $\begin{array}{l}\text { Turkish } \\
\text { Journal of } \\
\text { lnternal } \\
\text { Medicine }\end{array}$ & $\begin{array}{l}\text { Department of Infectious Disease, Canakkale Onsekiz Mart University, Faculty of Medicine, Canak- } \\
\text { kale, Turkey } \\
\text { E-mail:sevil3910@gmail.com }\end{array}$ & 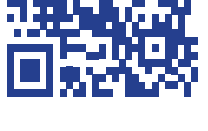 \\
\hline
\end{tabular}


diagnosis; due to our endemic region, Borrelia burgdorferi IgM and IgG, $C$. burnetii Phase 1 IgM and IgG and Phase 2 IgM and IgG, West Nile Virus PCR, Brucella Rose Bengal and tube agglutination, laboratory tests were studied from the serum using the indirect fluorescent antibody test method. In addition, abdominal ultrasonography was performed. Blood and urine cultures were negative.

Finally, serology for $\mathrm{Q}$ fever by indirect immunofluorescence assay showed $C$. burnetii IgG Phase 1: negative; IgG phase 2: positive at 1/64 titer and of IgM phase 2: positive at 1/96 titer. The patient was diagnosed as acute $\mathrm{Q}$ fever disease. The treatment was changed to doxycycline tablet $2 \times 100 \mathrm{mg} /$ day. Transthoracic electrocardiography was performed to investigate cardiac valvular disease, no valvular pathology was detected. His complaints had regressed and discharged on the 10th day of hospitalization, with the completion of the doxycycline treatment to 14 days, with the recommendation of outpatient clinic control.

Coxiella burnetii is an intracellular gram-negative bacterium and is the causative agent of $\mathrm{Q}$ fever, a zoonosis first seen in Australia in 1937. It can cause endemics around the world. People usually get the disease by inhaling the contaminated aerosol produced by infected livestock. Contaminated milk, intradermal inoculation, sexual contact, blood transfusion, and transplacental may also occur as a mode of transmission.

Acute infection is typically asymptomatic but may manifest as a febrile flu-like illness, pneumonia, hepatitis, and central nervous system infection. During the course of the disease that cannot be distinguished from other pneumonia clinically; 2-10 fold increase in liver function tests, leukocytosis and thrombocytopenia, erythrocyte sedimentation rate and creatine kinase increase may be seen or laboratory findings may also be normal. An immunofluorescent antibody test, which is a serological reference method, should be requested from patients suspected for the diagnosis of $\mathrm{Q}$ fever. ${ }^{3-7}$

Q fever should be considered in the differential diagnosis, especially in endemic areas. While some of the acute $\mathrm{Q}$ fever cases are asymptomatic, symptoms such as limited fever, headache, muscle- joint pain and cough are observed in 90\%.$^{3-9}$ Similar symptoms are present in the COVID-19 probable case definition. The disease may present at an early stage without pulmonary findings. ${ }^{1,2}$ Also, the presented case had fever, headache, abdominal pain, nausea, vomiting, cough and sputum for 4-5 days, and as its pandemic period diagnosis could be confused with COVID-19. The diagnosis of presented case was confirmed by serologic methods, as we are in the endemic zone and we suspected $Q$ fever.

Park et al. ${ }^{9}$ reported a 37-year-old male patient with co-infection with COVID-19 and $\mathrm{Q}$ fever. Therefore, $\mathrm{Q}$ fever should be considered in the differential diagnosis of COVID-19 or coinfection, especially in endemic areas.

\section{References}

1. WHO COVID-19 Case definition. Available at: https://www. who.int/publications/i/item/WHO-2019-nCoV-Surveillance_ Case_Definition-2020.2. Accessed March 1, 2021.

2. COVID-19 Rehberi. Available at: https://covid19.saglik.gov. tr/TR-66301/covid-19-rehberi.html. Accessed March 1, 2021.

3. Eldin C, Mélenotte C, Mediannikov O, Ghigo E, Million M, Edouard S, Mege JL, Maurin M, Raoult D. From Q fever to Coxiella burnetii infection: a Paradigm Change. Clin Microbiol Rev. 2017 Jan;30(1):115-90. doi: 10.1128/ CMR.00045-16.

4. Köksal E, Günal Ö, Kılıç SS. Q fever: An occupational disease. Klimik Derg. 2020 August 28;33(2):195-6 (in Turkish). doi: 10.5152/kd.2020.42.

5. Asan A. Q ateşi. In: Timurkaynak F, Yavuz SŞ, eds. KLİMİK 2015 XVII. Türk Klinik Mikrobiyoloji ve İnfeksiyon Hastalıkları Kongresi, Kongre Kitab1. 25-29 Mart 2015 Antalya;87-8.

6. Çelebi B, Baş B, Bali EA, Yavuz SŞ. First Isolation of Coxiella burnetii in Turkey from a Patient with Endocarditis; Antigen Production and Phase Change Study. Mikrobiyol Bul. 2019 Jul;53(3):274-84 (in Turkish). doi: 10.5578/mb.68336.

7. Coleman JJ, Manavi K, Marson EJ, Botkai AH, Sapey E. COVID-19: to be or not to be; that is the diagnostic question. Postgrad Med J. 2020;96(1137):392-8. doi: 10.1136/ postgradmedj-2020-137979.

8. Vink M, Vink-Niese A. Could cognitive behavioural therapy be an effective treatment for long COVID and post COVID-19 fatigue syndrome? Lessons from the Qure Study for Q-Fever Fatigue Syndrome. Healthcare (Basel). 2020 Dec 11;8(4):552. doi: 10.3390/healthcare8040552.

9. Park HS, Bae PK, Jeong HW, Son BR, Shin KS. Serological evidence of Coxiella burnetii and SARS-CoV-2 co-infection: A case report. Ann Lab Med. 2021;41(5):510-3. doi: 10.3343/ alm.2021.41.5.510. 